ISSN: 0514-7336

DOI: http://dx.doi.org/10.14201/zephyrus201473133147

\title{
PRÁCTICAS DE SACRIFICIO EN EL CERRO DE LA MESA (ALCOLEA DE TAJO, TOLEDO): EL DEPÓSITO RITUAL DE LA CASA 1
}

\section{Practices of sacrifice at the Cerro de la Mesa (Alcolea de Tajo, Toledo): the ritual deposit of the Casa 1}

\author{
Ana CABrera DíEz* y Marta Moreno-García** \\ * Dpto. de Prehistoria. Facultad de Geografía e Historia. C/ Profesor Aranguren, s/n. 28040 Madrid. Correo-e: \\ anacabre@ghis.ucm.es \\ ** Instituto de Historia. Centro de Ciencias Humanas y Sociales. CSIC. Cl Albasanz, 26-28. 28037 Madrid. \\ Correo-e:marta.moreno@cchs.csic.es
}

Recepción: 7/11/2013; Revisión: 6/02/2014; Aceptación: 17/03/2014

BIBLID [0514-7336 (2014) LXXIII, enero-junio; 133-147]

\begin{abstract}
RESUMEN: Los depósitos con restos óseos animales enterrados bajo el pavimento en ámbitos domésticos forman parte de prácticas rituales bien conocidas en la Protohistoria peninsular, tradicionalmente asociadas a la fundación o remodelación de nuevos edificios o a ritos vinculados a la propiciación y la fertilidad. Aunque los ejemplos mejor estudiados se encuentran en la zona levantina, el fenómeno también se conoce en yacimientos del interior. Este artículo tiene por objeto presentar un depósito ritual excavado en el poblado vetón del Cerro de la Mesa, en el valle medio del Tajo, cuyas características formales lo emparentan con las ofrendas domésticas de la zona ibérica. Se trata de un hoyo situado en el umbral de la Casa 1, que contiene los restos seleccionados de varios ovinos y un pequeño cuenco cerámico colocado en posición invertida. El análisis de los restos óseos, el contenido del cuenco y el estudio del contexto arqueológico en que se situaba el depósito han permitido relacionarlo con prácticas de sacrificio y libación dentro del marco de la religiosidad vetona. Este trabajo pretende igualmente contribuir a la formación de un corpus peninsular de inhumaciones rituales de animales en contextos domésticos, que impulse el adecuado estudio de la ritualidad protohistórica.

Palabras clave: Iberia. Meseta Sur. II Edad del Hierro. Vetones. Ofrenda doméstica. Ovinos. Religiosidad.
\end{abstract}

ABSTRACT: Deposits with animal bones remains buried under the floor in domestic areas, are well known ritual practices in the Peninsular Iron Age. These practices are traditionally associated either with foundation of new buildings or refurbishment, or linked to propitiation rites and fertility. Although best studied examples are in the east coast of Spain, the phenomenon is also known in other archeological interior sites. This paper presents a ritual deposit, dug in the veton settlement of Cerro de la Mesa, in the Tagus river middle basin, whose formal characteristics relate it to domestic offerings of the Iberian area. This pit, located at the threshold of the Casa 1, contains selected remains of several sheep and a small ceramic bowl placed upside down. The analysis of the skeletal remains, together with the contents of the bowl and the study of the archaeological context, have allowed to relate it with sacrifice and libation practices within the framework of vetonian religiosity. The aim of this paper is to contribute to the formation of a peninsular corpus of ritual domestic deposits contributing to study of the religious practices.

Key words: Iberia. Southern Plateau. Second Iron Age. Vetons. Domestic offering. Sheep. Religiosity. 


\section{El Cerro de la Mesa ${ }^{1}$}

Es un poblado vetón situado en el valle medio del Tajo, en una zona limítrofe entre las provincias de Toledo y Cáceres. Administrativamente pertenece al municipio de Alcolea de Tajo y está próximo a la pedanía de El Bercial y a la población de Puente del Arzobispo (Fig. 1). El cerro se ubica en el margen derecho del río Tajo, frente a la confluencia de este con el río Huso. Se trata de una zona estratégica que controla el histórico vado de Puente Pino, en uso desde el Bronce Final hasta época medieval (Chapa y Pereira, 2006). arqueológicas destacadas entre las que puede citarse una muralla que circunda la parte superior del cerro, y en la que se han reconocido varios momentos constructivos entre el s. VII a. C. y los inicios del s. VI a. C., con trabajos de reconstrucción y refuerzos posteriores (Ortega y Del Valle, 2004: 176-177), una posible zona de santuario situada en un sector amortizado de esta muralla, y una serie de estructuras de habitación dentro de la zona amurallada, que corresponden a la última fase de la ocupación vetona, a finales del s. II o inicios del s. I a. C. (Ortega y Del Valle, 2004: 180-181).

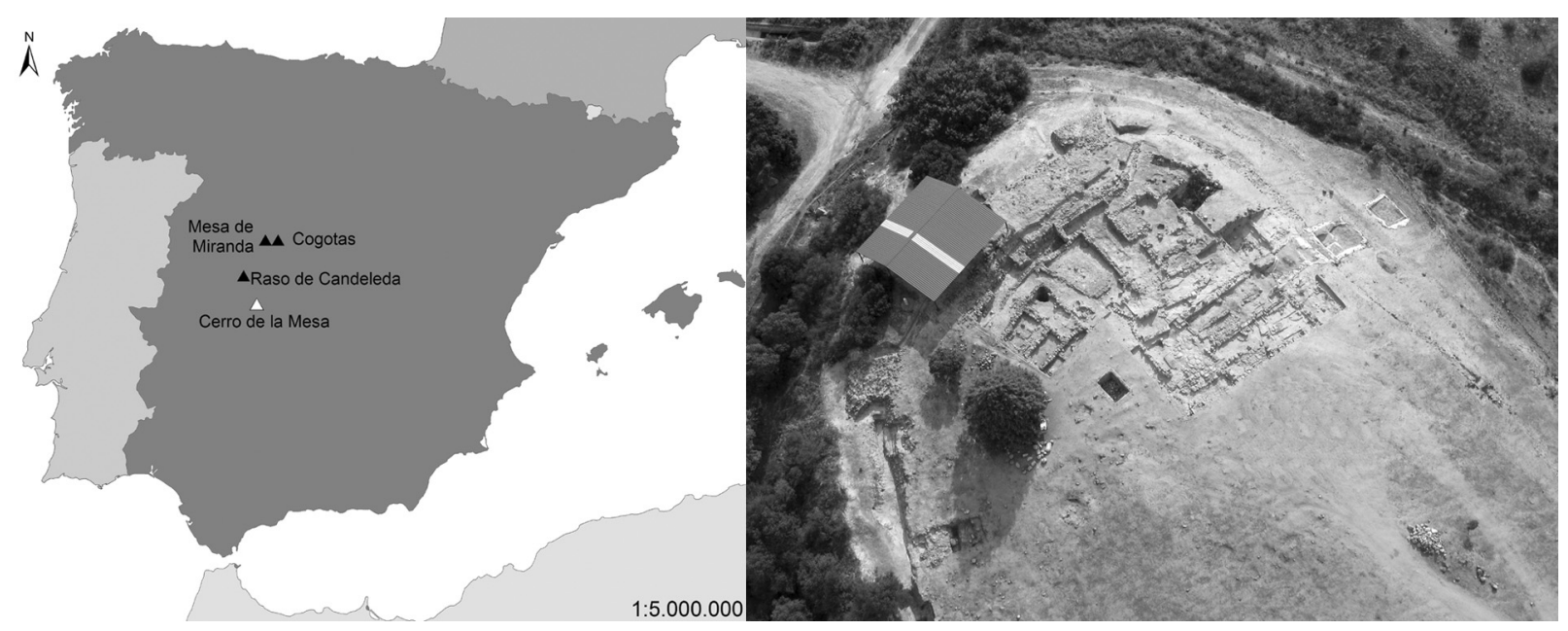

Fig. 1. Localización del Cerro de la Mesa y vista general de la zona excavada.

La superficie original del cerro ha sufrido importantes transformaciones en época reciente, debidas a la construcción del embalse de Azután (1969), con cuyos trabajos están relacionadas las primeras intervenciones en el yacimiento a partir de los ańos 90 (Almagro-Gorbea et al., 1999; Ortega y Del Valle, 2004; Chapa y Pereira, 2006; Chapa et al., 2007). Estas primeras campañas permitieron localizar diversas estructuras

${ }^{1}$ Este trabajo se enmarca en el proyecto HAR2011/ 25191: "Identidad y territorio en el valle medio del Tajo durante el Bronce Final y la Edad del Hierro" del Ministerio de Economía y Competitividad. Agradecemos los comentarios y sugerencias a T. Chapa y J. Pereira, y el trabajo con los mapas a C. Charro.
A partir de 2004 se reanudaron las excavaciones sistemáticas bajo la dirección de J. Pereira y T. Chapa, prolongándose los trabajos hasta 2010. En estas campañas se ha ampliado la excavación de la zona de habitación al so de las viviendas previamente exhumadas. De gran interés ha sido igualmente la excavación de una fosa-vertedero, subyacente a las viviendas vetonas, que inicialmente se relacionó con los posibles desechos de la zona de santuario, pero que tras su estudio reciente se ha asociado con la remodelación del poblado vetón (Chapa et al., 2013).

En esta última fase de los trabajos, han salido a la luz dos estructuras de habitación adosadas, un recinto abierto situado ante ellas y una serie de calles para el tránsito (Chapa et al., 2007; Charro 
y Cabrera, 2011). Las dos viviendas paralelas, denominadas Casa 1 y Casa 2, tienen una disposición interna similar consistente en un pequeño corredor de acceso que da paso a una gran habitación con hogar en el centro. Junto al pasillo de entrada y separado de este por muros medianeros, se disponen sendas habitaciones rectangulares empedradas que podrían interpretarse como pequeños corrales. Al E de las dos casas, y coincidiendo con el acceso, se localiza un gran patio empedrado en el que se exhumaron varios recipientes cerámicos de almacenaje y una serie de instrumentos metálicos de trabajo como cuchillos y hoces.

A pesar de sus semejanzas estructurales, las dos casas presentan singularidades en cuanto a su estratigrafía y sus materiales asociados. Mientras que la Casa 2 apareció prácticamente vacía tras un probable proceso de abandono, la Casa 1, por el contrario, se encontraba repleta de materiales cerámicos, metálicos y líticos. Además esta vivienda daba muestras evidentes de haber sufrido un incendio que no afectó a las estructuras anexas pero que determinó el hallazgo in situ de numerosos materiales. Entre estos se incluyen varios recipientes cerámicos de almacenaje, algunos asociados a restos de cereal y leguminosas, y elementos de vajilla como platos, vasitos y tapaderas. Es destacable también la existencia de varios vasos fenestrados completos localizados en torno al hogar central. Igualmente abundantes son los materiales metálicos relacionados con el trabajo artesanal -tijeras, hoces, picos, clavos, pinzas- o con la elaboración de productos textiles -pesas de telar, fusayolas y agujas de bronce-. De la misma manera hay que resaltar la presencia de una serie de objetos singulares concentrados todos al este del gran hogar. Se trata de un hacha de piedra pulimentada, una hoz de hierro con improntas de espigas de cereal, un cuchillo afalcatado, un posible gancho de carne, un asa de caldero con decoración de palmetas y un disco de plomo. En la misma habitación apareció una fíbula de bronce de tipo caballito (Chapa et al., 2007: 808, fig. 6), un pendiente amorcillado de bronce y un anillo de plata.

\section{El depósito del Cerro: catalogación de un nuevo complejo ritual}

La excavación de la Casa 1 ha podido realizarse de forma íntegra y, además de proporcionar el interesante conjunto de materiales citado, ha permitido conocer tanto la estructura interna de la vivienda como la entrada a este recinto en la zona septentrional de la casa y a través del gran patio empedrado. Precisamente fueron los trabajos en la zona de acceso, llevados a cabo durante la campańa de 2008, los que sacaron a la luz un depósito de restos animales enterrados bajo el nivel de uso. Se trata de una pequeña fosa al oeste del umbral de entrada, excavada en un pavimento de ladrillos de adobe (Fig. 2). La fosa es rectangular, de unos $30 \times 38 \mathrm{~cm}$ y una profundidad máxima de unos $10 \mathrm{~cm}$. En su interior había un conjunto de huesos de animales y un pequeño cuenco de cerámica a mano depositado en posición invertida (Fig. 3).

Los restos óseos recuperados ascienden a 66 piezas, que representan un número mínimo de 5 animales (Fig. 4). De acuerdo con los criterios morfológicos propuestos por Boessneck (1969) y

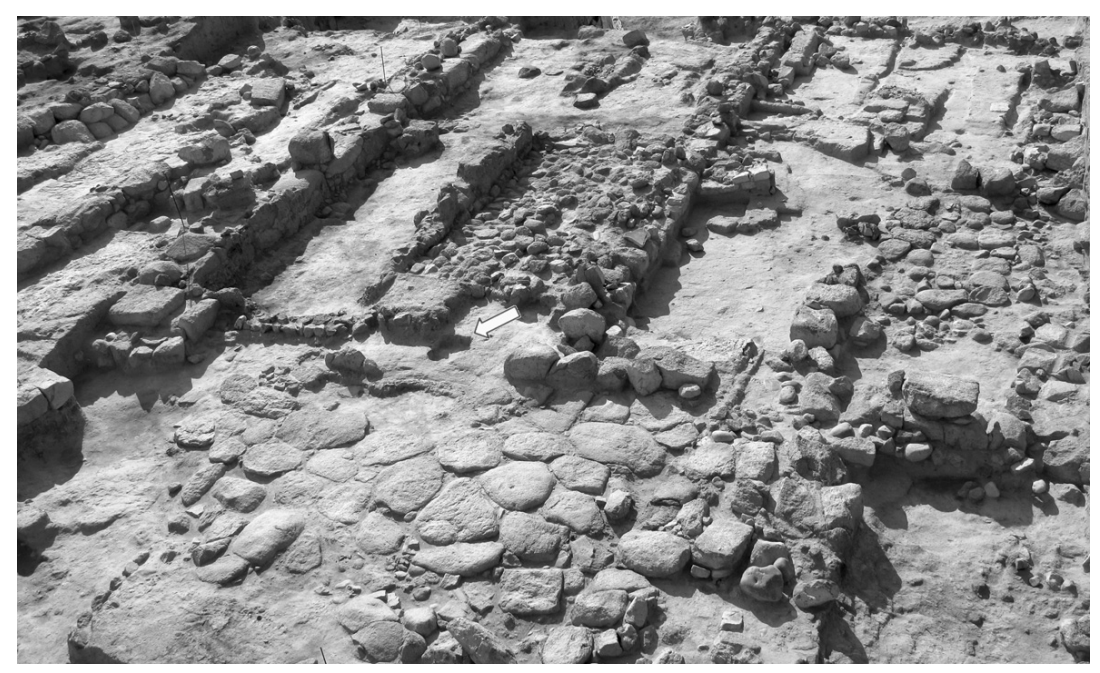

FIG. 2. Situación del depósito en la Casa 1. 


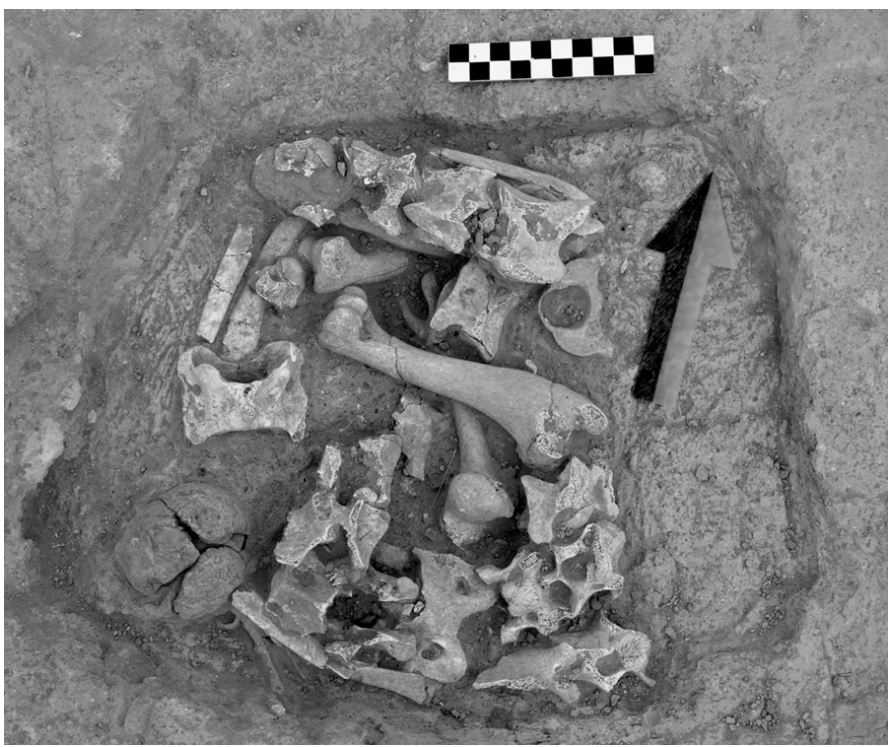

FIG. 3. Depósito de la Casa 1.

la comparación realizada con la colección de referencia del CCHS-CSIC todos ellos pertenecen a ovinos -Ovis aries-. Las porciones esqueléticas identificadas corresponden a la región cervical del esqueleto axial -atlas, axis y vértebras cervicales-, costillares y la parte superior del cuarto delantero derecho representado por los húmeros de cuatro individuos. Sin embargo, el NMI en el depósito deriva de la presencia de 5 atlas - primera vértebra cervical-, elemento anatómico único en el esqueleto. El perfil sexual de estos restos resulta difícil de calcular dado su grado de fragmentación. En el caso de los atlas, uno de los criterios utilizados es la morfología de los procesos transversales que en las ovejas terminan en forma apuntada, mientras que en los carneros son romos y de forma más irregular (Boessneck, 1969). En todos los ejemplares esta parte está mal conservada. Pero sí pudimos observar en 4 de los 5 atlas que el arco ventral es menos grueso en la entrada de la vértebra media, en la dirección dorsoventral, que el diámetro de altura del canal ventral suprayacente, lo que parece indicar que pertenecerían a hembras. Por otro lado, uno de los axis mejor conservados presenta un ensanchamiento en la terminación caudal de la apófisis espinosa, característica de individuos machos. En conclusión, y con la debida cautela por los datos disponibles, parece que se depositaron las porciones cervicales - pescuezos- de 4 ovejas y 1 carnero.

La falta de conexión anatómica que existe entre los huesos de la región cervical, del costillar y del cuarto anterior no permite afirmar que los elementos óseos depositados pertenezcan a los mismos animales. Si bien es cierto que el estado de fusión epifisaria de las epífisis a las diáfisis de los húmeros y los discos vertebrales a los cuerpos de las vértebras -todos ellos aún sin consolidarindican que todos los animales sacrificados eran subadultos, de una edad en torno a los tres ańos y medio (Silver, 1969). Es decir, se trata de ovinos que estarían muy próximos de alcanzar su peso máximo y en edad reproductora, que habrían podido proporcionar leche, en el caso de las hembras, y lana antes de ser sacrificados.

Como fue evidente durante la excavación las vértebras cervicales de 3 individuos se encontraban en conexión anatómica parcial, lo que sugiere que los pescuezos no fueron desarticulados y, probablemente, tampoco descarnados. Por el contrario, la ausencia de la parte proximal de las costillas y de las vértebras torácicas, con las cuales articulan, refleja que los lomos fueron procesados y la zona menos carnosa del costillar fue desechada aquí. En el caso de los húmeros se procedió a su separación de las escápulas -paletillas- y la parte inferior de las patas delanteras. Esta operación se llevó a cabo con bastante cuidado, como demuestra la recuperación de los huesos completos, sin tajos o seccionados en las articulaciones.

\begin{tabular}{|l|c|c|}
\hline \multicolumn{1}{|c|}{ HUESO } & N.o & NMI \\
\hline Atlas & 5 & 5 \\
\hline Axis & 4 & 4 \\
\hline Vértebra cervical & 13 & - \\
\hline Fragmentos de vértebra & 22 & - \\
\hline Costilla & 18 & - \\
\hline Húmero & 4 & 4 \\
\hline Total & $\mathbf{6 6}$ & \\
\hline
\end{tabular}

FIG. 4. Relación de elementos anatómicos y NMI (Número Minimo de Individuos). 
Se observaron varios cortes transversales, muy finos y superficiales, en la norma y en la tuberosidad ventral de dos de los atlas (Fig. 5), además de en los cuerpos de 5 costillas y en la parte lateral y medial de los cóndilos distales de 3 de los 4 húmeros. La precisión en la ejecución y el perfil en V observado bajo una lupa binocular de la parte interna de las incisiones sugieren el uso de una lámina metálica afilada. El origen de tales trazas de manipulación responde a diferentes aspectos relacionados con la obtención de las porciones anatómicas presentes en la inhumación y, por tanto, se identifican con el despiece primario de la carcasa. Comenzando con los atlas, la ubicación de los cortes en la parte superior de su ala derecha evidencia que la cabeza del animal fue

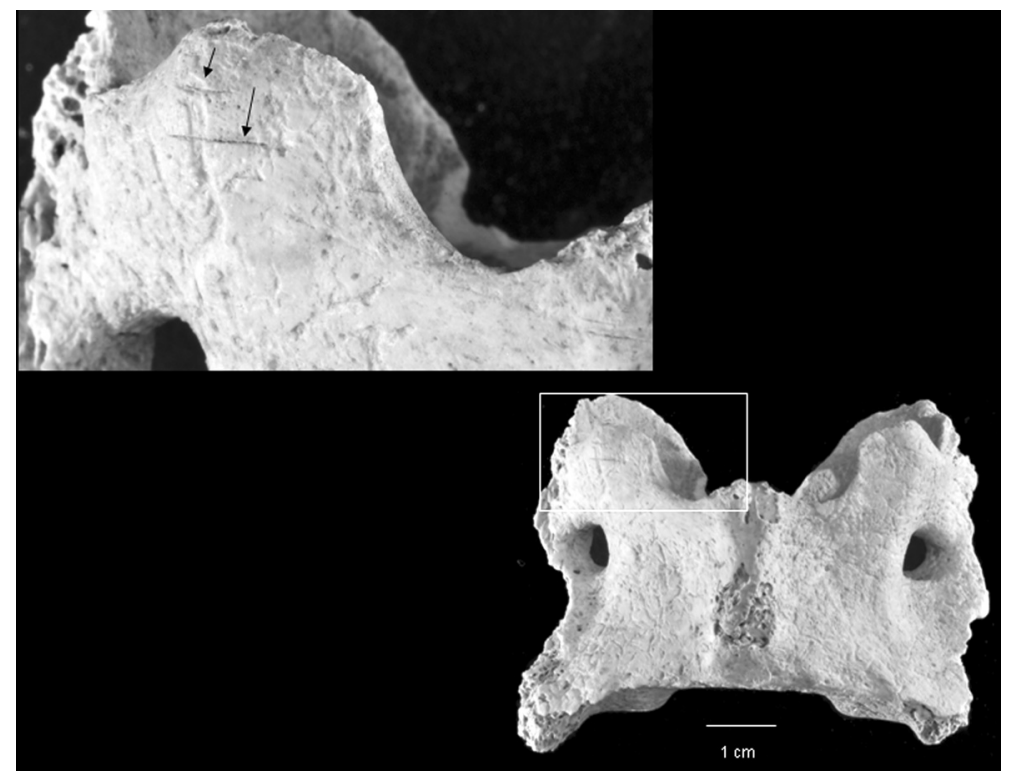

FIG. 5. Atlas de Ovis aries en norma ventral y detalle de la incisión transversal en la tuberosidad ventral. empujada hacia arriba para, desde la zona de la garganta, facilitar la separación del cráneo del resto del cuerpo. Se podría argumentar que estas marcas se produjeron durante el sacrificio de los animales como consecuencia del degüello y posterior desangrado, según se presenta en el exvoto conocido como El Sacrificador, procedente de La Puerta del Segura, Jaén; esta figura ha sido interpretada como un sacerdote sacrificando un carnero, al que sujeta con el brazo izquierdo mientras en la mano derecha alza un cuchillo afalcatado (Fig. 6). Sin embargo, debido a nuestra experiencia en la preparación de carcasas de animales, hemos podido comprobar en numerosas ocasiones que el corte de la yugular, si es realizado por una persona habituada a practicar este tipo de acto, no llega al hueso y, por tanto, no deja marcas evidentes. De hecho, de los 5 atlas solo 2 presentaban incisiones. La separación de la cabeza es una operación más compleja que implica el seccionado del paquete muscular que envuelve la articulación occipital del cráneo con el atlas, siendo necesario realizar cortes más profundos durante los que, a menudo, la lámina del utensilio cortante utilizado entra en contacto con el hueso. La orientación de los cortes sugiere que las carcasas se encontraban en posición horizontal.

Las incisiones observadas en los cuerpos de las costillas se relacionan con el eviscerado y el fileteado de la carne de los lomos, mientras que las marcas en la parte distal de los húmeros pudieron producirse al separar estos huesos de la articulación del codo. No hay evidencias de cortes a lo largo de las diáfisis -cañas- que sugieran descarnado ni consumo de tuétano. Tampoco se registraron marcas de termoalteración producidas por fuego. Por todo ello nos inclinamos a pensar que estas porciones fueron depositadas con la carne. Las fracturas presentes son de origen reciente, debidas a la propia fragilidad de los huesos y a factores diagenéticos que habrán contribuido a alterar las estructuras óseas.

Junto a los restos de fauna, el depósito contenía un pequeño cuenco de cerámica común a mano de factura tosca (Fig. 7). Se trata de un recipiente de cerámica oxidante irregularmente cocida, de borde recto y labio apuntado, con base cóncava y una pequeña carena en la parte superior. Presenta indicios de la acción del fuego tanto en las paredes interiores como en las exteriores.

El cuenco fue sometido a un análisis de su contenido mediante cromatografía de gases-espectometría de masas ${ }^{2}$. Este análisis reveló la presencia de

\footnotetext{
${ }^{2}$ Informe realizado por ARTE-LAB. S.L.
} 


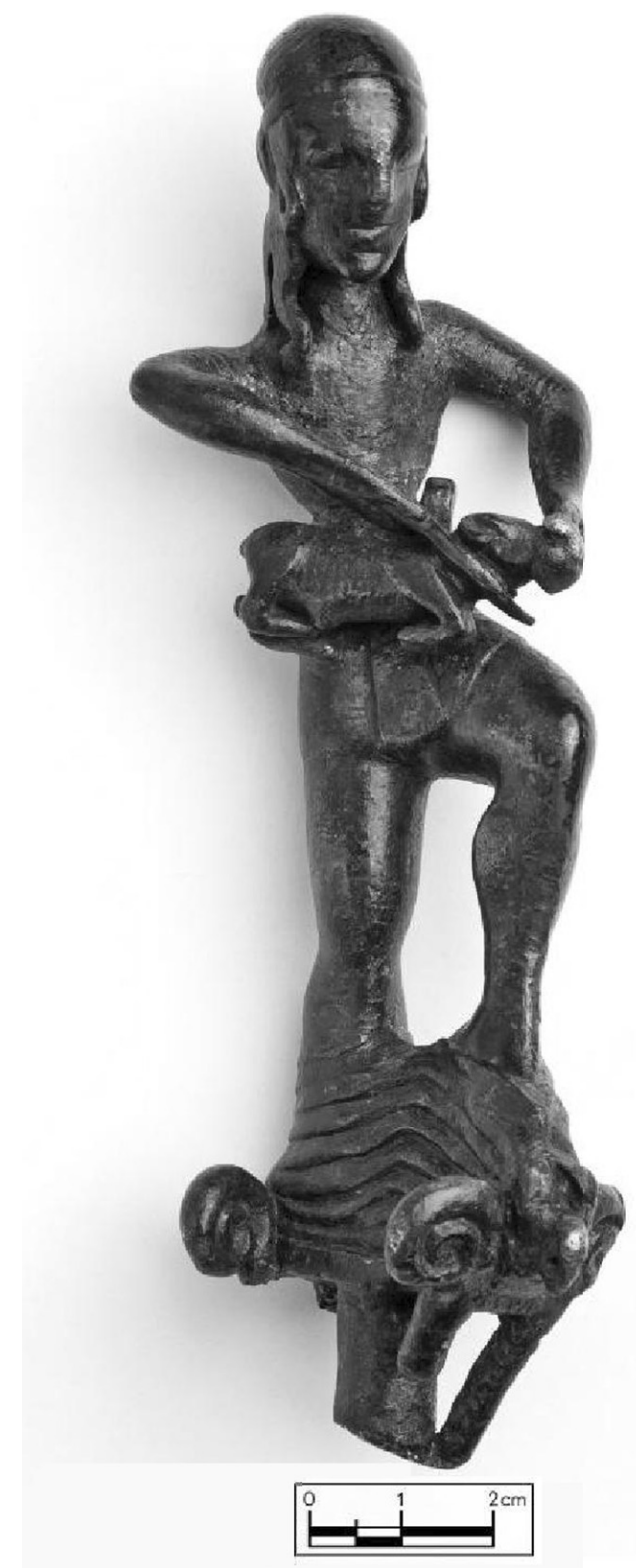

FIG. 6. El Sacrificador de La Puerta del Segura, Jaén (imagen de R. Fernández Ruiz, MAN, CER.es [http://ceres.mcu.es]).

varios ácidos grasos de procedencia tanto vegetal como animal. Entre los primeros, se han detectado restos de ácido azelaico, mirístico y oleico. Junto a ellos aparecen indicios de ácido palmitoleico y oleico, frecuentes en grasas animales o aceites de pescado. La heterogeneidad de los restos no hace fácil precisar la naturaleza exacta del contenido del recipiente, aunque parece que puede confirmarse alguna sustancia formada por una mezcla de elementos de origen animal y vegetal.

\section{El ritual del depósito}

\subsection{El patrón de inhumación}

Las características formales de esta inhumación animal responden a un patrón de enterramiento intencionado parecido al que en otros yacimientos se ha asociado a prácticas de tipo ritual. Sin embargo, antes de hacer esta asociación de manera automática, creemos necesario explicitar los criterios que apoyan tal afirmación. Las prácticas de tipo ritual responden a una serie de características que han sido estudiadas desde la antropología y la historia de las religiones (Bell, 1992). De forma general puede afirmarse que se trata de prácticas destinadas a establecer una comunicación simbólica con la divinidad a través de acciones reguladas formalmente de modo minucioso, y realizadas de forma repetitiva, fija y con voluntad de permanencia a lo largo del tiempo. Estas características dejan ciertas evidencias en el registro arqueológico que pueden ser rastreadas. Para el caso que nos ocupa y siguiendo los criterios propuestos en un trabajo anterior ${ }^{3}$ se puede llamar la atención sobre los siguientes aspectos:

\subsubsection{Selección de porciones esqueléticas}

Los restos del depósito no han sido enterrados de forma aleatoria. Por el contrario, el estudio faunístico revela una clara selección en lo que se refiere a las especies y las partes esqueléticas depositadas. Todos los restos pertenecen a ovinos subadultos y probablemente están representadas mayoritariamente hembras. Lo más llamativo, no obstante, son los huesos depositados. Se trata de varias vértebras cervicales, de las que al menos 4

${ }^{3}$ Cabrera Díez, A. (2010): El ritual del sacrificio de animales en la Cultura Ibérica. Una perspectiva arqueológica. Tesis doctoral presentada en 2010 en la Univ. Complutense de Madrid (http://eprints.ucm.es/11714/1/T32477.pdf). 

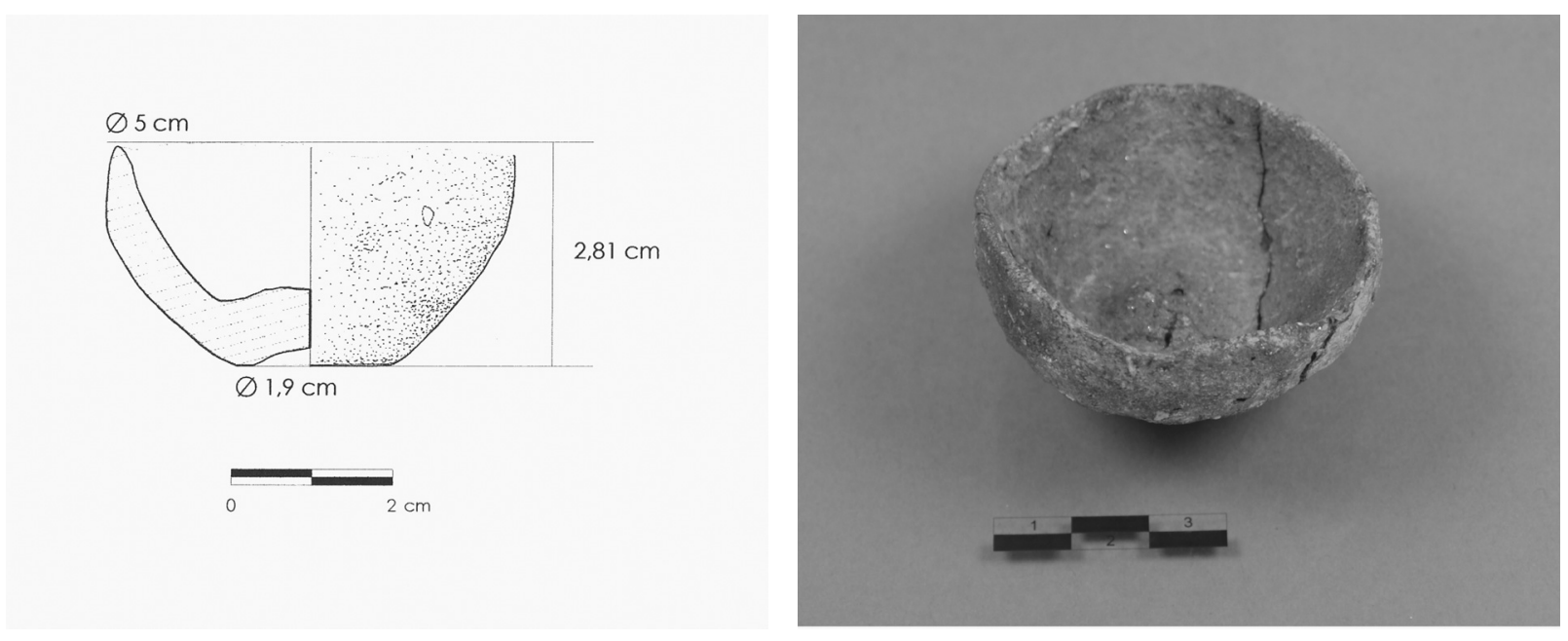

FIG. 7. Recipiente cerámico incluido en el depósito.

estaban en conexión anatómica, varios fragmentos de la parte central de las costillas y 4 húmeros, todos ellos del lado derecho.

Este muestrario de restos nos habla de un tratamiento diferencial claro del cuerpo de la víctima que se manifiesta de forma evidente en los restos elegidos para enterrar y que probablemente tiene un correlato en el reparto sacrificial de la carne. Es posible pensar en un rito en el que los restos del animal sacrificado son repartidos entre los participantes del ritual y la divinidad. La ausencia en el depósito de las partes esqueléticas con mayor contenido cárnico, así como de las extremidades del lado izquierdo del animal, permite proponer que el rito aquí documentado incluyera un tratamiento distinto para estos huesos ausentes que se relacionaría con su desecho tras el consumo de la carne por parte del oficiante o de los participantes, o bien su consagración en el altar tal y como se hacía en el mundo grecolatino (Vernant, 1989; Scheid, 1993). Explicar este patrón como consecuencia de procesos tafonómicos, ya sean bioestratinómicos -anteriores al enterramiento- o diagenéticos - posteriores a su incorporación en el depósito- parece fuera de lugar ya que la representatividad esquelética se vería afectada en cuanto a la presencia de elementos anatómicos frágiles, pero no favorecería apenas la preservación de los huesos de uno de los miembros ni la presencia de restos articulados.

\subsubsection{Características del contenedor y aspecto formal del depósito}

Otros de los aspectos que deben considerarse son los que afectan a las características de la estructura contenedora y a la forma en la que las porciones cárnicas son depositadas en la fosa. Por lo que respecta a la estructura contenedora, se trata como ya se ha apuntado de un hoyo cuadrangular excavado directamente en la arcilla que formaba el pavimento de la última fase de ocupación de la Casa 1. La fosa estaba tapada por el mismo barro del pavimento y no se encontró ninguna laja de piedra o cualquier otra señalización. Los restos tampoco estaban en un recipiente cerámico sino en contacto directo con el suelo.

En cuanto a la disposición de la ofrenda, llama la atención la clara intención con la que las porciones cárnicas fueron formalmente colocadas en el agujero, para ajustarlas a las dimensiones del mismo. En el proceso de excavación se apreció su distribución en dos capas distintas. Los húmeros estaban depositados en el centro del espacio, dos de ellos cruzados entre sí, las vértebras se situaban encima, rellenando los espacios laterales, y los fragmentos de costillas estaban relegados a la zona más externa, encintando todo el depósito. En la esquina So de la fosa se situaba el pequeño cuenco de cerámica a mano que había sido enterrado boca abajo. 


\subsection{Sacrificio y otras ofrendas}

Uno de los elementos más singulares del depósito del Cerro de la Mesa es la presencia del pequeño cuenco de cerámica a mano. La inhumación de objetos cerámicos en los depósitos votivos con fauna es un hecho poco habitual tanto en el contexto ibérico (Belarte y Chazelles, 2011: 171) como en aquellos ejemplos que se conocen en el interior peninsular. Habitualmente la presencia de cerámica en estos conjuntos se circunscribe a recipientes de tamaño medio que cumplen una función de contenedor de los restos óseos depositados -así ocurre, por ejemplo, en los depósitos conocidos en la Mesa de Miranda y Azaila-. Por el contrario, el ejemplar cerámico del Cerro de la Mesa cumple una función distinta con implicaciones de tipo ritual.

La posición invertida en la que fue colocado en la fosa nos podría remitir a prácticas de libación que serían ejecutadas en asociación con el sacrificio animal. La libación es un elemento bien documentado dentro de la religiosidad vetona a partir, tanto de ciertos elementos arquitectónicos presentes en edificios de culto -receptáculos y canales de Panoias, Ulaca (Álvarez-Sanchís, 2003: 310)-, como de elementos de vajilla específica -jarras y aguamaniles de bronce- procedentes sobre todo de necrópolis (ibidem: 179). De forma habitual, las prácticas de libación vetonas se asocian a la ofrenda de agua o de sangre sacrificial. En este caso, el análisis del contenido de nuestro pequeño cuenco parece eliminar estas posibilidades. Aunque ya se ha señalado la dificultad de precisar el contenido exacto, puede indicarse a modo de hipótesis la posibilidad de que el preparado contuviera algún tipo de leche animal. Algunos de los ácidos detectados -ácido oleico C:18:1, ácido palmítico C:16 y ácido esteárico C:18, estos dos últimos mayoritarios en la muestra- representan juntos un $72 \%$ de los ácidos grasos existentes en la grasa de la leche.

Alternativamente se puede sugerir que el cuenco fuese destinado a contener ofrendas de tipo sólido. Hay que recordar que las dimensiones del recipiente son notablemente pequeñas -el diámetro máximo de la boca es de $5 \mathrm{~cm}$ y la profundidad máxima no llega a los $3 \mathrm{~cm}$ - con una capacidad útil de unos $43 \mathrm{~cm}^{3}$. Además, la morfología del cuenco no es la más adecuada para contener y verter un líquido, al tratarse de un recipiente poco profundo, de borde irregular y con un labio recto y apuntado en vez de presentar una boca exvasada. Hay que añadir, por último, que el análisis químico reveló que los restos contenidos en el cuenco no se encontraron en la tierra que rellenaba el depósito y que fue igualmente analizada.

Por otra parte, este pequeño recipiente presentaba indicios de la acción del fuego postcocción. No puede descartarse que su contenido fuese quemado y estuviera en relación con alguna sustancia olorosa o con la iluminación -presencia de ácido oleico-. Con relación a estas prácticas merece la pena destacar que entre los materiales cerámicos encontrados en la habitación central de la Casa 1 se halló un conjunto de al menos 4 vasos fenestrados similares a otros ejemplares conocidos en la Meseta norte y en el so, que se vinculan con una funcionalidad como quemadores o incensarios (Berrocal, 1992: 107-109).

En cualquier caso parece claro que el cuenco enterrado junto a los huesos fue hecho expresamente para el papel funcional que se le asignó en el ritual. Su importancia se deduce del hecho de que fue depositado de forma excepcional junto a los otros restos de la ceremonia.

\subsection{Situación del depósito en la casa}

Por último, entre los elementos de interés del depósito tratado hay que llamar la atención sobre la ubicación concreta que tiene dentro de la estructura de la Casa 1. Como se ha señalado ya, la vivienda cuenta con dos zonas diferenciadas separadas por un muro de tapial. La zona principal está formada por una habitación rectangular con un gran hogar central a la que se accede por un pasillo estrecho, dispuesto en el mismo eje. Al oeste de estas dos estancias y de forma contigua al pasillo, se dispone un recinto rectangular empedrado que ha sido interpretado como un posible corral. El acceso a ambas zonas de la casa se produce a través de dos entradas diferentes situadas en la zona N. Cada una de ellas está marcada claramente por sendos umbrales con agujeros de poste y quicialeras. En este contexto, es llamativo constatar que la fosa con los restos óseos se sitúa 
en un pequeño espacio con el suelo de tierra bati$\mathrm{da}$, inmediatamente después del umbral que antecede el empedrado del corral. Así pues, el depósito ritual no está asociado con la parte "noble" de la casa ni con el hogar central. Tampoco está colocado en un lugar apartado, asociado a esquinas o muros como ocurre a menudo en el patrón que se reitera para los depósitos de fundación. Por el contrario el depósito de la Casa 1 está vinculado a un espacio de tránsito que habría que atravesar obligatoriamente para acceder al corral.

\section{Los depósitos animales en el contexto peninsular}

Las inhumaciones de animales jóvenes situadas bajo el pavimento de contextos domésticos son un fenómeno bien documentado en la Protohistoria peninsular. Los ejemplos mejor conocidos se concentran en la zona NE, donde el fenómeno ha sido objeto de estudio desde hace tiempo (Oliver, 1996; Belarte y Sanmartí, 1997; Gusi y Muriel, 2008), llegándose a considerar un fenómeno ritual específico de la II Edad del Hierro en esta región y poniéndose en relación con los ejemplos conocidos al otro lado de los Pirineos, en el Languedoc francés (Fabre, 1990; Columeau, 1991; Belarte y Chazelles, 2011).

La frecuencia de aparición de estos depósitos domésticos ha permitido incluso establecer tipologías (Miro y Molist, 1990) y apuntar hipótesis sobre su significado religioso. En los últimos años, el desarrollo de los estudios arqueofaunísticos aplicados a los restos procedentes de contextos rituales ha enriquecido la perspectiva del fenómeno y ha proporcionado nuevos datos, sobre todo para la región catalana (Valenzuela, 2008; Albizuri, 2011) ${ }^{4}$.

Si bien estos depósitos domésticos de animales jóvenes parecen concentrarse en los contextos domésticos del levante peninsular, donde se encuentran los ejemplos mejor estudiados, no

${ }^{4}$ Cf. también Nieto Espinet, A.: Entre el consum i l'afecte. La interacció entre els animals $i$ les comunitats protohistòriques de la plana occidental catalana (segles VII-IV a. C). Tesis doctoral inédita presentada en 2012 en la Univ. de Lérida. puede decirse que se trate de un fenómeno exclusivo del ámbito ibérico. Desde hace tiempo se han ido dando a conocer ejemplos puntuales en yacimientos celtibéricos, vacceos y vetones, y cada vez son más los datos que invitan a pensar que tampoco en estos ámbitos se trata de un fenómeno excepcional. Es cierto, sin embargo, que en los ejemplos del interior peninsular el patrón de enterramiento no es tan regular como en el NE, ni formal ni cronológicamente. Parece evidente que la mayor variedad cultural y geográfica se traduce en prácticas rituales con significado e intención diversos que hacen más difícil cualquier estudio comparativo. Tampoco ayuda el hecho de que los trabajos específicos de síntesis sobre el tema son aún escasos para esta región (Alfayé, 1997, 2009: 315 ss.; 2010, 2011).

Sin embargo, en el interior peninsular la inhumación ritual de restos animales en contextos domésticos tiene una larga tradición que puede remontarse en el tiempo a cronologías de la Edad del Bronce e incluso el Calcolítico bien sistematizada recientemente por Liesau (2012). Con cronologías más modernas y paralelos formales más próximos al depósito del Cerro de la Mesa, estas prácticas están documentadas en el yacimiento de Melgar de Abajo (Cuadrado y San Miguel, 1993: 313; San Miguel, 1995: 312-313), en el Soto de Medinilla (Liesau, 1994; Morales y Liesau, 1995), en el Alto de la Cruz, Cortes de Navarra (Maluquer et al., 1990: 30), en la Corona de Manganeses, Zamora (Misiego et al., 2013: 222-227), en El Castillejo de Fuensaúco, Soria (Romero y Misiego, 1995: 132) o en el Soto de Bureba, Burgos (Sanz, 2000: 407). Estas prácticas se extienden incluso a momentos plenamente romanos en lugares tales como en el yacimiento de Pintia (Sanz y Velasco, 2003), en Uxama (García y Sánchez, 1996) o en Mirobriga (Barata, 1999) (Fig. 8).

En el territorio vacceo se sitúan los paralelos cronológicos más cercanos. Por ejemplo, en el yacimiento de Melgar de Abajo, Valladolid, se localizó un depósito datado en plena ocupación vaccea, además de otro perteneciente a la primera ocupación. Este depósito del Hierro II consiste en un hoyo circular excavado parcialmente bajo el suelo, que contenía en su interior los restos de un pequeño ovicáprido (Cuadrado y San Miguel, 1993: 316). De cronología semejante se considera 
el llamado 'conjunto-ofrenda' del Soto de Medinilla, Valladolid, encontrado en los niveles del Soto III. Se trata de 4 cráneos de vaca alineados en un semicírculo, junto con numerosas astas mudadas de ciervo y otros huesos largos de vaca (Morales y Liesau, 1995: 458-459).

También se pueden recordar aquí los interesantes depósitos múltiples en territorio vacceo y el enterramiento de una oveja del poblado de Pintia, con una cronología más tardía del s. I d. C (Sanz y Velasco, 2003: 81; Alberto y Velasco, 2003: 126-133).

Más al N, puede citarse igualmente el depósito del castro de la Corona de Corporales, León, datado en un momento inmediatamente anterior a la romanización. En una esquina de la Construcción 2 del sector I apareció bajo el pavimento un hoyo de unos $25 \mathrm{~cm}$ de profundidad y 22 de diámetro, con las paredes delimitadas por cantos medianos y tapado con una laja delgada y recortada en forma aproximadamente circular. Este hoyo contenía en su interior las extremidades de lo que parece un ejemplar adulto de cabra -Capra hircus (SánchezPalencia y Fernández Posse, 1985: 24 y 327)-.

De gran interés son también los ejemplos conocidos en la provincia de Álava, donde los depósitos animales se relacionan, igual que en el NE peninsular, con inhumaciones infantiles. Así se documenta en el poblado de Atxa, donde se descubrió un depósito compuesto por cuernos de bovino -Bos taurus- y 2 astas de ciervo-Cervus elaphus-, que se encontraban en una cubeta con restos óseos infantiles. Este yacimiento ha proporcionado otros depósitos formados por cráneos de ovicápridos y que se han relacionado con prácticas rituales colectivas destinadas a proteger los límites del asentamiento o con depósitos de fundación (Filloy, 1995: 193; Alfayé, 2009: 316). La vinculación de los depósitos de animales con inhumaciones infantiles se repite en el poblado de La Hoya, Laguardia. En el llamado 'Recinto 41', interpretado por su excavador como un edificio público de carácter comunitario, aparecieron varios depósitos de animales junto a enterramientos infantiles (Llanos, 2002: 74; 2005; Alfayé, 2009: 207).

Los depósitos que conocemos en zona celtibérica no se corresponden con la tipología de inhumaciones en contextos domésticos, aunque sí se han identificado depósitos relacionados con murallas y estructuras defensivas y se han constatado también depósitos con inhumaciones infantiles, por ejemplo, en el Castro de la Coronilla, Guadalajara (Cerdeño y García Huerta, 1992).

En el territorio estrictamente vetón los ejemplos de que disponemos son muy escasos. El paralelo más próximo al del Cerro de la Mesa se encuentra en la llamada Casa $\mathrm{C}$ del poblado abulense de la Mesa de Miranda, en Chamartín de la Sierra. En ella se excavó un depósito en la dependencia D7 consistente en una urna cerámica con su tapadera, enterrada en el suelo y rodeada de piedras y adobes. Formaban parte del conjunto el asa de un caldero de hierro, un canto rodado de granito con pintura negra en una de sus caras y la mandíbula de un suido (López García, 2012: 109-110, lám. 37).

En general, es llamativo comprobar que los paralelos formales más próximos al ejemplar del Cerro de la Mesa no se encuentran dentro de su propio contexto geográfico-cultural a pesar de que, como se ha visto, el corpus con el que contamos es aún muy limitado. De cualquier modo, con el repertorio disponible hoy, es posible afirmar que nuestro depósito toledano tiene claras semejanzas con las inhumaciones animales de la zona ibérica del NE peninsular. Puede decirse, incluso, que no resultaría difícil incorporarlo a los ejemplares que han servido para establecer una caracterización tipológica de los depósitos de la zona, en yacimientos como la Penya del Moro (Miró y Molist, 1990). Así, en función de los restos esqueléticos enterrados nuestro depósito tiene similitudes con los que las autoras clasificaban como depósitos de 'tipo B', que contienen restos de huesos largos, costillas, cintura escapular y pélvica, y vértebras. Como se ha visto, a excepción de los restos de escápula y pelvis, las demás categorías están bien representadas en el depósito doméstico del Cerro de la Mesa. Otros depósitos ibéricos semejantes al de nuestro ejemplar vetón se encuentran en los poblados levantinos de Puig de la Nao, Castellón (Oliver, 2006: 212); de Can Oliver, Barcelona (Albizuri, 2011: 86-87), o de Els Vilars, Gerona 5 .

\footnotetext{
${ }^{5}$ Nieto: op. cit. n. 4: 622-632.
} 


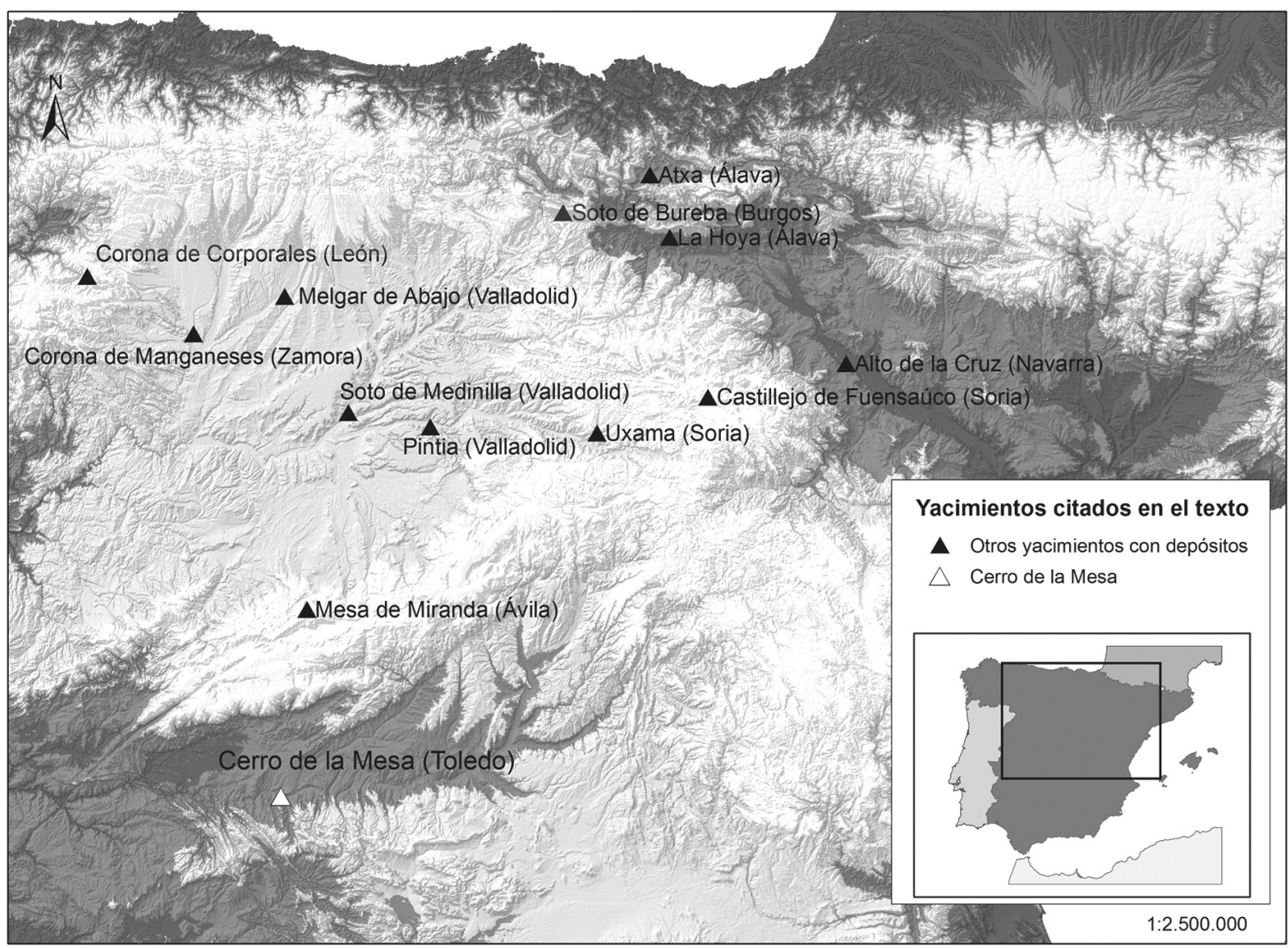

FIG. 8. Mapa con la localización de los yacimientos citados en texto en los que se han constatado depósitos de animales.

\section{Conclusiones}

La singular inhumación animal de la Casa 1 invita a hacer algunas reflexiones sobre su posible sentido dentro del sistema ritual vetón, aún mal conocido. La interpretación tradicional de estos enterramientos domésticos bajo el pavimento los asocia con ofrendas de fundación realizadas con ocasión de la construcción o la remodelación de los distintos recintos, y es posible que este sea el caso de nuestro depósito. La fundación de la Casa 1 debió de producirse en algún momento entre comienzos del s. II a. C y mediados del s. I a. C., fecha en la que se produjo el incendio y la destrucción final de la vivienda. Este momento está bien datado con una fecha absoluta de C14 que lo sitúa en torno al
40 a. C. ${ }^{6}$. Es precisamente durante ese período, cuando documentamos en el yacimiento una clara reestructuración del espacio que afecta a la parte más alta del cerro en la que se encuentra la Casa 1. Las últimas campañas de excavación han permitido constatar la cuidada amortización vetona de las fases de ocupación antigua del yacimiento, con el objeto de habilitar esta zona prominente. Para ello se llevó a cabo una destacada inversión de trabajo que incluye la colmatación de una gran fosa sobre la que se asienta el nuevo trazado urbano, modificado sensiblemente con la construcción de casas y viales (Chapa et al., 2013). Es probable que haya que encuadrar

\footnotetext{
${ }^{6}$ BETA-252781 (1910+/- $\left.50 \mathrm{BP}\right)$, muestra sobre semilla.
} 
nuestra inhumación animal dentro de los ritos que acompañan este momento de cambios espaciales y reordenación del espacio urbano.

Por otra parte las características del recinto en el que se encuentra el depósito pueden incorporar nuevos componentes a la interpretación del mismo. Como ya se ha indicado, la Casa 1 acumula en su interior un extraordinario conjunto de objetos singulares cuya recuperación in situ se vio favorecida por el incendio que significativamente afectó a este recinto, pero no a las estructuras anexas. La concentración de algunos elementos de clara funcionalidad ritual como un asa de caldero con decoración de palmeta, un gancho de carne de bronce, un hacha de piedra pulimentada o varios vasos fenestrados, además de elementos de adorno personal vinculados a las élites aristocráticas -fíbula de caballito, anillo de plata, cuenta de oro- nos hacen proponer la hipótesis de que este espacio tuviera cierto sentido religioso dentro de la comunidad. En este caso el depósito cobraría una nueva perspectiva y más allá de la ofrenda doméstica se podría pensar en un rito que sancionase ante la comunidad la consagración de este espacio como lugar sacro. Se trataría así de un rito relacionado con la purificación o la lustración del recinto a la manera de los conocidos en Italia ${ }^{7}$.

En este sentido es muy significativa la posición de la inhumación junto a uno de los umbrales de entrada a la casa. Este espacio liminar es un lugar cuya importancia simbólica vinculada a la función separadora y diferenciadora que se asocia a los límites ha sido ya resaltado (Eliade, 1981: 373374). En efecto el umbral de la casa, de la misma manera que las murallas de un poblado, marcan física y simbólicamente una frontera que separa espacios de distinta naturaleza: lo privado y lo público, lo sagrado y lo profano, lo civilizado y lo salvaje... Es bien conocido en el mundo antiguo la existencia de ritos específicos asociados a la purificación o la protección de esta zona extrema especialmente expuesta a la contaminación religiosa. El ejemplo más ilustrativo es el que conocemos para el mundo itálico gracias a las Tablas Egubinas que describen con detalle los ritos necesarios para proteger adecuadamente la ciudad, y

${ }^{7}$ Catón, De agri. 134,141; Dionisio de Halicarnaso, Hist. Ant. de Roma VIII, 55, 3-5. que incluyen el sacrificio y la inhumación de víctimas concretas ante las puertas (Porzio Gernia, 2004). Aunque para el mundo vetón no tenemos tanta información, puede recordarse aquí la asociación de algunos verracos a las puertas de entrada de los poblados - casos de la Mesa de Miranda, Botija, Castillo de Bayuela...- en virtud de la cual se ha resaltado un posible sentido apotropaico de estas esculturas (Álvarez-Sanchís, 2007: 192) y su posible respuesta a una función religiosa semejante de protección o purificación de un espacio especial y bien delimitado.

En otro sentido, hay que resaltar que el acceso en el que se encuentra la ofrenda comunica un amplio patio empedrado con el corral de la casa. Se sitúa así en medio de un espacio agropecuario en el que se han recuperado utensilios -juego de bocados de caballo o tijeras de esquilar- que remiten a labores ganaderas y a la presencia de animales en el entorno de trabajo. Si tenemos en cuenta la importancia que estas actividades tienen en la economía de los pueblos vetones no es imposible que la ofrenda incluyera también ciertas connotaciones en relación con la protección o la fertilidad del ganado, así como con la propiciación del trabajo doméstico.

Las características específicas de la ofrenda pueden apoyar este punto. Como ha resaltado el estudio faunístico, los animales sacrificados parecen ser mayoritariamente hembras en edad reproductora, un tipo de víctima habitualmente asociado a la propiciación de la fertilidad. En general, la oveja es un animal bien documentado dentro del sistema sacrificial de los pueblos vetones (Sánchez Moreno, 2007: 135; Marco Simón, 2008). Es una de las tres víctimas presentes en el rito indoeuropeo de la suovetaurilia, en el que se hacía el triple sacrificio de una oveja, un cerdo y un toro, que se asocia a la lustración pero también a la propiciación agraria y a la fertilidad del ganado $^{8}$. Un rito parecido a este parece atestiguarse entre los pueblos del interior peninsular gracias a la inscripción lusitana de Cabeço das Fraguas, Guarda, donde se menciona el sacrificio de estos tres animales consagrados explícitamente a diversos dioses (Tovar, 1985). Aunque la interpretación de la inscripción es aún motivo de controversia, la

\footnotetext{
${ }^{8}$ Catón, De re rustica, 141.
} 
oveja parece ser el animal destinado a divinidades cuyos teónimos - Trebopala y Trebarune- se han relacionado con la raíz indoeuropea asociada a casa, ciudad, aldea, comunidad (ibidem: 234235). En el marco de la ideología trifuncional indoeuropea resaltada por Dumezil, la oveja parece ser la ofrenda asociada a los dioses de la tercera función -aquellos con connotaciones agrarias o divinidades tutelares de espacios domésticos(Santos, 2007). Si bien es cierto que no podemos afirmar algo tan concreto para el mundo vetón, no puede dejar de resaltarse este vínculo entre el sacrificio de ovejas y el deseo de protección y propiciación en un contexto doméstico.

Volviendo al depósito de nuestro yacimiento también puede recordarse como la posibilidad de que el ritual llevado a cabo incluyera la libación de leche vuelve a remitir a connotaciones religiosas de fertilidad. Sabemos por ejemplo cómo la libación de leche era la ofrenda preferida de la diosa Pales, una antigua divinidad romana de los rebaños y los pastores ${ }^{9}$.

En conclusión, estamos aún lejos de conocer con detalle las prácticas religiosas de los pueblos vetones y son enormes las dificultades para enmarcar adecuadamente el depósito del Cerro de la Mesa dentro del sistema de creencias de estos pueblos. La falta de detalle de la información publicada sobre inhumaciones domésticas similares impide hacer el adecuado trabajo de contraste y valoración de estas prácticas religiosas. Cabe esperar que futuros trabajos pongan el foco sobre un tipo de ritual que se intuye menos singular de lo que parece hasta ahora en el contexto cultural del interior peninsular, y que se pueda así seguir avanzando dentro de este campo. En este sentido, el presente trabajo pretende contribuir a la formación de un corpus peninsular de inhumaciones rituales domésticas que debe ser el paso previo para el correcto estudio de la ritualidad protohistórica.

\section{Bibliografía}

Alberto, V. y Velasco, J. (2003): "Perros, gatos, ovejas y cerdos: sacrificios de animales en Pintia”. En SanZ, C. y Velasco, J. (eds.): Pintia. Un oppidum

${ }^{9}$ Ovidio, Fastos, IV, 746. en los confines orientales de la región vaccea. Investigaciones Arqueológicas Vacceas, Romanas y Visigodas (1999-2003). Valladolid: Univ. de Valladolid, pp. 125-141.

Albizuri, S. (2011): "Depósitos de ovicaprinos en ámbito doméstico ibérico. El ejemplo del poblado de Ca n'Oliver (Cerdanyola del Vallès, Barcelona)", Archaeofauna, 20, pp. 85-101.

Alfayé, S. (1997): "Rituales relacionados con murallas en el ámbito celtibérico", Paleohispánica, 7, pp. 9-41.

Alfayé, S. (2009): Santuarios y rituales en la Hispania Céltica. Oxford: Archaeopress.

Alfayé, S. (2010): "Rituales de sangre: sacrificios cruentos en los ámbitos celtibérico y vacceo". En BurILlo, F. (ed.): Ritos y mitos. VI Simposio sobre Celtíberos. Zaragoza: Centro de Estudios Celtibéricos de Segeda, pp. 219-238.

Alfayé, S. (2011): Imagen y ritual en la Céltica peninsular. A Coruña: Toxosoutos

Almagro Gorbea, M.; Cano, J. J. y Ortega, J. (1999): "El anillo argénteo del Cerro de la Mesa (Toledo) y los anillos con caballito de la Hispania prerromana”, Complutum, 10, pp. 157-165.

ÁlvareZ-SAnchís, J. (2003): Los vetones. Madrid: RAH.

ÁlvareZ-SANChís, J. (2007): "Animales protectores en la cultura vetona: los verracos”. En BARRIL, M.; Galán, V.; Manso, E. y Ser Quijano, E. (eds.): Ecos del Mediterráneo: el mundo ibérico y la cultura vetona. (Exposición 2007, Torre de los Guzmanes, Ávila). Ávila: Diput. Prov. de Ávila. pp. 191-194.

Barata, M. F. (1999): "As habitaçóes de Miróbriga e os ritos domésticos romanos", Revista Portuguesa de Arqueologia, 2 (2), pp. 51-67.

Belarte, M. C. y Chazelles, C. A. (2011): "Les manifestations de practiques rituelles en contexte domestique en Ibérie et en Gaule méditerranéenne". En Roure, P. y Pernet, L. (eds.): Des Rites et des Hommes. Practiques symboliques des Celtes, des Ibères et des Grecs en Provence, en Languedoc et en Catalogne. Paris: Errance, pp. 165-188.

Belarte, M. C. y Sanmartí, J. (1997): "Espais de culte i pràctiques rituals a la Catalunya protohistòrica", Quaderns de prehistòria i arqueologia de Castelló, 18, pp. 7-32.

Bell, C. (1992): Ritual Theory, Ritual Practice. New York: OUP.

Berrocal, L. (1992): "Los pueblos Célticos del Suroeste de la Península Ibérica”, Complutum, n. ${ }^{\circ} 2$ extra, pp. 1-386.

Botssneck, J. (1969): "Osteological differences between sheep and goats". En BRothwell, D. y Higgs, E. S. (eds.): Science in Archaeology. 2. ${ }^{\text {a }}$ ed. London: Thames and Hudson, pp. 331- 358. 
Cerdeño, M. L. y García Huerta, R. (1992): El Castro de la Coronilla (Chera, Guadalajara) (19801986). Madrid: Instituto de Conservación y Restauración de Bienes Culturales.

Chapa, T. y Pereira, J. (2006): "Un vado perdido: El Cerro de la Mesa (Alcolea de Tajo, Toledo)", Zona Arqueológica, 7 (2), pp. 120-133.

Chapa, T.; Pereira, J.; Cabrera, A.; Charro, C.; Moreno, M.; Ruiz Alonso, M.; Pérez Díaz, S.; López SÁez, J. A. y Araujo, R. (2013): "Una fosa-vertedero de época vetona en el Cerro de la Mesa: (Alcolea de Tajo, Toledo)", Trabajos de Prehistoria, 70 (1), pp. 140-165.

http://dx.doi.org/10.3989/tp.2013.120106

Chapa, T.; Pereira, J.; Madrigal, A.; Perlines, M.; Fernández del Cerro, M.; Arcos, J. y Charro, C. (2007): "El asentamiento protohistórico del Cerro de la Mesa (Alcolea de Tajo, Toledo)". En Millán, J. M. y Rodríguez Ruza, C. (eds.): Arqueología de Castilla-La Mancha. I Jornadas (Cuenca 2005). Cuenca: UCL-Junta de Comunidades de CLM, pp. 797-809.

Charro, C. y Cabrera, A. (2011): "El yacimiento arqueológico del Cerro de la Mesa y su entorno (Alcolea de Tajo, Toledo)". En López García, J. P.; Hernández SÁnchez, D. y García SÁnchez, J. (eds.): Los vínculos entre el hábitat y el paisaje. (Actas I Congreso de Arqueología de Chamartín (Ávila), 2010). Madrid: La Ergástula, pp. 209-218.

Columeau, P. (1991): L'animal pour l'homme. Recherches sur l'alimentation carnée dans le sud de la France du Néolithique au Moyen-Âge d'après les vestiges osseux. I. Le monde rural. Travaux du centre Camille Jullian. Aix en Provence: CNRS.

Cuadrado, M. A. y San Miguel, L. C. (1993): "El urbanismo y la estratigrafía del poblado vacceo de Melgar de Abajo". En Romero CARNICERO, F.; SANZ Mínguez, C. y Escudero, Z. (eds.): Arqueología vaccea. Estudios sobre el mundo prerromano en la cuenca media del Duero. Valladolid: JCyL, pp. 303-334.

ELIADE, M. (1981): Tratado de historia de las religiones. Morfología y dinámica de lo sagrado. Madrid: Edic. Cristiandad.

FABRE, V. (1990): "Rites domestiques dans l'habitat de Lattes: sépultures et dépôts d'animaux", Lattara, 3, pp. 391-416.

Filloy, I. (1995): "Los depósitos rituales". En GiL Zubillaga, E. (ed.): Atxa. Poblado indígena y campamento militar romano. Vitoria-Gasteiz: Museo de Arqueología de Álava, pp. 191-193.

García Merino, C. y SÁnchez Simón, M. (1996): "Enterramiento infantil bajo un pavimento de la Casa de los Plintos de Uxama", Celtiberia, 90, pp. 203-214.
Gusi i Jener, F. y Muriel, S. (2008): "Panorama actual de la investigación de las inhumaciones infantiles en la Protohistoria del Sudoeste mediterráneo europeo". En GUSI I Jener, F.; MuRIEL, S. y OlÀRIA, C. (eds.): Nasciturus, infans, puerulus vobis mater terra. La muerte en la infancia. Castellón: Diput. de Castellón, pp. 257-329.

LIESAU, C. (1994): Contribución al estudio arqueofaunistico durante la Edad del Hierro en la Submeseta Norte de la Peninsula Ibérica. Madrid: UAM.

Liesau, C. (2012): "Depósitos con ofrendas de animales en yacimientos de Cogotas I: antecendentes y características". En RodríGUez MarCos, J. A. y Fernández Manzano, J. (eds.): Cogotas I. Una cultura de la Edad del Bronce en la Península Ibérica. Valladolid: Univ. de Valladolid-JCyL, pp. 219-257.

Llanos, A. (2002): Gentes del Hierro en privado. La casa en la Edad del Hierro en Álava. Vitoria-Gasteiz: Museo de Arqueología de Álava.

Llanos, A. (2005): Mil años de vida en el poblado berón de La Hoya (Laguardia: Álava): guía del yacimiento y del museo. Vitoria: Serv. de Public. de Dpto. de Cultura, Juventud y Deportes.

López García, J. P. (2012): Arqueología de la Arquitectura en el mundo vetón. La casa $C$ de la Mesa de Miranda. Madrid: edic. La Ergástula.

Maluquer de Motes, J.; Gracia, F. y Munilla, G. (1990): "Alto de la Cruz (Cortes, Navarra). Campañas 1986-1988", Trabajos de Arqueología de Navarra, 9, pp. 11-245.

Marco Simón, F. (2008): "El horizonte simbólico: dioses y espacios de culto", Zona Arqueológica, 12, pp. 276-289.

Miró, C. y Molist, N. (1990): "Elements de ritual doméstic al poblat ibèric de la Penya del Moro", Zephyrus, XLIII, pp. 311-319.

Misiego, J. C.; Martín Carbajo, M. A.; Marcos, G. J. y SANZ García, F. J. (2013): Las excavaciones arqueológicas en el yacimiento de "La CoronalEl Pesadero" en Manganeses de la Polvorosa. La Edad del Hierro y la Época Romana en el norte de la provincia de Zamora. Memorias Arqueología en Castilla y León, 19. Edición electrónica: JCyL.

Morales, A. y Liesau, C. (1995): "Análisis comparado de las faunas arqueológicas en el valle Medio del Duero (prov. Valladollid) durante la Edad del Hierro". En Delibes de Castro, G.; Romero, F. y Morales, A. (eds.): Arqueología y Medio Ambiente. El Primer Milenio a. C. en el Duero Medio. Valladolid: JCyL, pp. 455-514.

Oliver, A. (1996): "Fauna y vegetación en los ritos cultuales ibéricos", Quaderns de prehistòria i arqueologia de Castelló, 17, pp. 281-308. 
Oliver, A. (2006): El Puig de la Nau, Benicarló. Castellón: Proyecto Cultural de Castellón.

Ortega, J. y Valle, M. D. (2004): "El poblado de la Edad del Hierro del Cerro de la Mesa (Alcolea de Tajo, Toledo): primeros resultados", Trabajos de Prehistoria, 61 (1), pp. 175-185.

Porzio, M. L. (2004): Offerta rituales e mondo divino. Contributo all'interpretazione delle Tavole di Gubbio. Alessandria: Edizioni dell'Orso.

Romero, F. y Misiego, J. C. (1995): "Desarrollo secuencial de la Edad del Hierro en el Alto Duero: El Castillejo (Fuensaúco, Soria)". En Burillo, F. (ed.): Poblamiento Celtibérico. III Simposio sobre los Celtiberos. Zaragoza: Inst. Fernando el Católico, pp. 127-139.

SAN Miguel, L. C. (1995): "Notas sobre la secuencia y características arqueológicas del yacimiento de la Edad del Hierro de Melgar de Abajo (Valladolid)". En Delibes de Castro, G.; Romero, F. y MoraLES, A. (eds.): Arqueología y Medio Ambiente. El Primer Milenio a. C. en el Duero Medio. Valladolid: JCyL, pp. 307-317.

SÁnchez Moreno, E. (2007): "Aproximación a la religión de los vetones", Studia Zamorensia, 4, pp. 115-147.

Sánchez-Palencia, J. y Fernández-Posse, M. D. (1985): La Corona y el Castro de Corporales I. Truchas (León). Campañas de 1978 a 1981. Madrid: EAE.

Santos, M. J. (2007): "El sacrificio en el Occidente de la Hispania romana. Para un nuevo análisis de los ritos de tradición indoeuropea", Paleohispánica, 7, pp. $175-217$.

Sanz Mínguez, C. y Velasco, J. (2003): Pintia. Un oppidum en los confines orientales de la región vaccea. Investigaciones arqueológicas vacceas, romanas y visigodas (1999-2003). Valladolid: Univ. de Valladolid.

Sanz Serrano, R. (2000): "Soto de Bureba en el marco de la antigua Austrigonia”. En PARzinguer, H. y Sanz Serrano, R. (eds.): Das Castro von Soto de Bureba. Archéologische und historidche Forschungen zur Bureba in vorrömischer und römeischer Zeit. Randen/Westfalia: DAI, pp. 365-462.

ScheID, J. (1993): "La spartizione sacrificale a Roma". En Grottanelli, C. y Parise, N. F. (eds.): Sacrificio e società nel mondo antico. Roma: ed. Laterza, pp. 267-292.

SILVER, I. A. (1969): "The ageing of domestic animals". En Brothwell, D. y HigGs, E. S. (eds.): Science in Archaeology. 2. ${ }^{\mathrm{a}}$ ed. London: Thames and Hudson, pp. 283-302.

Tovar, A. (1985): "La inscripción del Cabeço das Fráguas y la lengua de los lusitanos". En DE Hoz, J. (ed.): Actas del III Coloquio sobre lenguas y culturas paleohispánicas. Lisboa, 1980. Salamanca: Univ. de Salamanca, pp. 227-254.

Valenzuela, S. (2008): "Ofrenes animals al jaciment ibèric d'Alorda Park (Calafell, Baix Penedès)". En Miñarro, M. y Valenzuela, S. (eds.): Actes I Congrés de Joves Investigadors en Arqueologia dels Països Catalans: la Protohistoria als Pasios Catalans: (Vilanova del Camí, 2005). Barcelona: Univ. de Barcelona-Ayunt. de Vilanova del Camí, pp. 151-158.

VERnANT, J. P. (1989): “At man's table: Hesiod's foundation myth of sacrifice". En Detienne, M. y Vernant, J. P. (eds.): The cuisine du sacrifice among the Greeks. Chicago: Chicago University Press, pp. 21-86. 